\title{
Correction to: Prevalence of vitamin D deficiency and its predictors in the Portuguese population: a nationwide population-based study
}

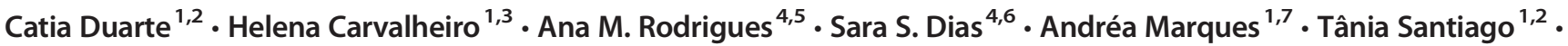 Helena Canhão $0^{4,8,9}$. Jaime Cunha Branco ${ }^{4,10}$. José António Pereira da Silva ${ }^{1,2}$}

Published online: 2 April 2020

(C) International Osteoporosis Foundation and National Osteoporosis Foundation 2020

\section{Correction to: Archives of Osteoporosis (2020) 15:36 https://doi.org/10.1007/s11657-020-0695-x}

The original version of this article, published on 02 March 2020 unfortunately contained an error on "Fig. 3 Prevalence of Vitamin D Levels by NUTSII. The prevalence estimated values represent weighted values to the Portuguese Adult Population in 2011 [33], considering the study design." The percentage of individuals with levels $\geq 20 \mathrm{ng} / \mathrm{mL}$ in Açores is $18 \%$ instead of $28 \%$.

The corrected figure is given below.

The authors regret their error.
The online version of the original article can be found at https://doi.org/ $10.1007 / \mathrm{s} 11657-020-0695-\mathrm{x}$

Catia Duarte

catiacmduarte@gmail.com

1 Department of Rheumatology, Centro Hospitalar e Universitário de Coimbra, Praceita Prof. Mota Pinto, 3000-075 Coimbra, Portugal

2 Coimbra Institute for Clinical and Biomedical Research (iCBR)-Faculty of Medicine, University of Coimbra, Azinhaga Santa Comba, Celas, 3000-548 Coimbra, Portugal

3 Center for Neuroscience and Cell Biology, Faculdade de Medicina, University of Coimbra, Rua Larga, Pólo I, $1^{\circ}$, 3004-504 Coimbra, Portugal

4 EpiDoC Unit, CEDOC, NOVA Medical School, Universidade Nova de Lisboa (NMS-UNL), Rua Câmara Pestana, nº 6, 6-A Edificio CEDOC II, 1150-082 Lisbon, Portugal

5 Faculdade de Medicina, Universidade de Lisboa, Avenida Professor Egas Moniz, 1649-028 Lisbon, Portugal
6 Center for Innovative Care and Health Technology (ciTechCare), Escola Superior de Saúde de Leiria (ESSLei), Instituto Politécnico de Leiria (IPLeiria), Campus 2-Morro do Lena-Alto do Vieiro, Apartado 4137, 2411-901 Leiria, Portugal

7 Health Sciences Research Unit: Nursing Coimbra, Coimbra Nursing School, ESEnfc, Avenida Bissaya Barreto, Apartado 700, 3046-851 Coimbra, Portugal

8 National School of Public Health, Universidade Nova de Lisboa, Avenida Padre Cruz, 1600-560 Lisbon, Portugal

9 CHLC - Hospital Curry Cabral, Rua da Beneficência n. ${ }^{\circ}$, 1069-166 Lisbon, Portugal

10 Rheumatology Department, Centro Hospitalar de Lisboa Ocidental Egas Moniz Hospital, Rua da Junqueira, 126, 1349-019 Lisbon, Portugal 


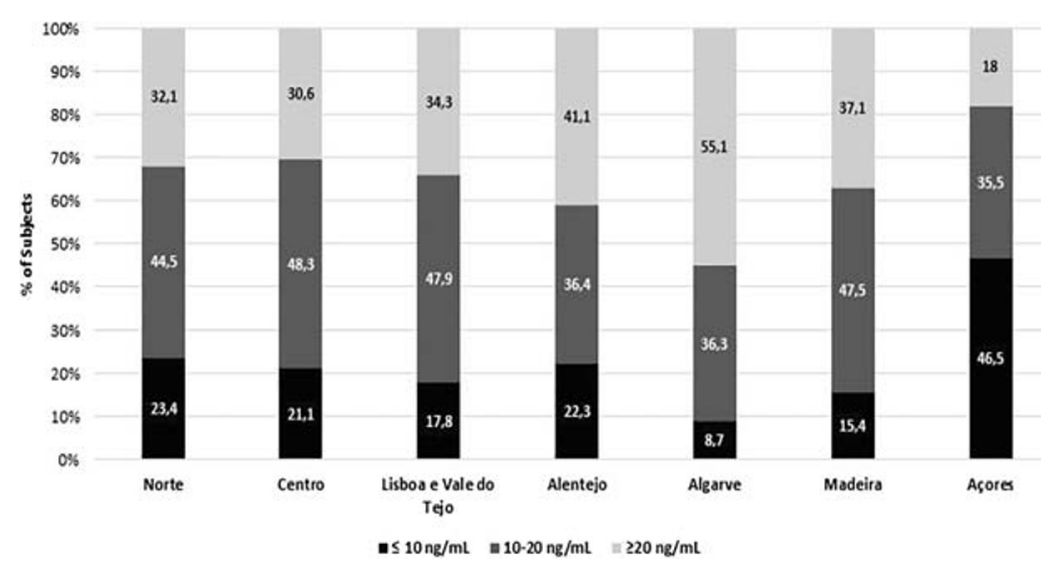

Publisher's note Springer Nature remains neutral with regard to jurisdictional claims in published maps and institutional affiliations. 